\title{
Perbedaan Pengaruh Latihan Menendang Menggunakan Bending dan Menendang Menggunakan Karet Terhadap Power Otot Tungkai dan Long Passing Sepakbola Pada Usia 13-14 Tahun Sekolah Sepakbola Klumpang Putra
}

\author{
Muhammad Rizfan, Ibrahim Wiyaka \\ Fakultas Ilmu Keolahragaan, Universitas Negeri Medan \\ muhammadrizfan04@gmail.com,ibrahimwiyaka10@gmail.com
}

\begin{abstract}
Abstrak: Tujuan penelitian untuk mengetahui perbedaan pengaruh latihan menendang menggunakan bending dan menendang menggunakan karet terhadap power otot tungkai dan long passing sepakbola pada usia 13-14 tahun sekolah sepakbola klumpang putra tahun 2019. Metode penelitian yang digunakan metode eksperimen. Populasi penelitian ini adalah siswa sekolah sepakbola klumpang putra berusia 13-14 tahun berjumlah 25 orang. Sampel diperoleh dengan teknik purposive sampling sebanyak 20 orang. Hasil uji hipotesis 1 diperoleh $t_{\text {hitung }}>t_{\text {tabel }}(10.046>1.833)$ menunjukkan bahwa terdapat pengaruh yang signifikan dari latihan menendang menggunakan bending terhadap peningkatan power otot tungkai. Uji hipotesis 2 diperoleh $\left(t_{\text {hitung }}>t_{\text {tabel }}(5.377>1.833)\right.$ menunjukkan bahwa terdapat pengaruh yang signifikan dari latihan menendang menggunakan karet terhadap peningkatan power otot tungkai. Uji hipotesis 3 diperoleh $t_{\text {hitung }}>t_{\text {tabel }}(4.744>1.734)$ menunjukkan bahwa latihan menendang menggunakan bending secara signifikan lebih baik dari pada latihan menggunakan karet terhadap peningkatan power otot tungkai pada siswa sekolah sepakbola Klumpang Putra. Uji hipotesis 4 diperoleh $\mathrm{t}_{\text {hitung }}>\mathrm{t}_{\text {tabel }}(6.022>1.833)$ menunjukkan bahwa terdapat pengaruh yang signifikan dari latihan menendang menggunakan bending terhadap hasil long passing. Uji hipotesis 5 diperoleh $t_{\text {hitung }}>\mathrm{t}_{\text {tabel }}(7.508>1.833)$ menunjukkan bahwa ada terdapat pengaruh yang signifikan dari latihan menendang menggunakan karet terhadap hasil long passing. Uji hipotesis 6 diperoleh $\mathrm{t}_{\text {hitung }}<\mathrm{t}_{\text {tabel }}(0,252<1.734)$ menunjukkan bahwa latihan menendang menggunakan bending tidak lebih besar pengaruhnya dari pada latihan menggunakan karet terhadap peningkatan hasil long passing pada atlet sekolah sepakbola Klumpang Putra usia 13-14 tahun.
\end{abstract}

Kata Kunci: Bending, Karet, Otot tungkai, Long pass

\section{The Difference Between Effects of Kicking Exercises Using Bending and Kicking Using Rubber Against Leg and Muscle Power Long Passing Football at the age of 13-14 Years of the Klumpang Putra Soccer School}

\begin{abstract}
The purpose of this study was to determine the differences in the effect of kicking exercises using bending and kicking using rubber on leg muscle power and soccer long passing at the age of 1314 years old, male sports school football in 2019. The research method used was the experimental method. The population of this research is 25 students from Klumpang soccer school students aged 13-14. Samples were obtained by 20 purposive sampling techniques. Hypothesis 1 test results obtained $t$ count $>t$ table $(10,046>1,833)$ show that there is a significant effect of kicking exercises using bending to increase leg muscle power. Hypothesis 2 test obtained ( $t$ count $>t$ table $(5,377>1,833)$ shows that there is a significant effect of kicking exercises using rubber to increase leg muscle power. Hypothesis 3 test obtained $t$ counts $>t$ table $(4,744>1,734)$ shows that kicking practice uses bending significantly better than training using rubber to increase leg muscle power in Klumpang Putra soccer school students. Hypothesis 4 test obtained t count $>t$ table $(6,022>1,833)$ shows that there is a significant effect of kicking exercise using bending on long passing results. Hypothesis 5 test results
\end{abstract}


obtained $t$ count $>t$ table $(7.508>1,833)$ shows that there is a significant effect of kicking exercises using rubber on the results of long passing. Hypothesis 6 test obtained $t$ counts $<t$ table $(0.252$ $<1.734)$ shows that the kicking exercise using bending has no greater effect than a practice using and rubber against increasing long passing results in Klumpang Putra soccer school athletes aged 13-14 years.

Keywords: Bending, Rubber, Leg muscle, Long pass

\section{PENDAHULUAN}

Olahraga merupakan aktifitas fisik yang mana tujuan olahraga adalah mencapai prestasi setinggi tingginya dengan semaksimal mungkin bagi mereka baik yang individu maupun tim. Untuk mendapatkan prestasi di bidang olahraga yang digeluti diharapkan mendapat ilmu pengetahuan dan teknologi yang kegunaannya tepat. Tercapainya prestasi dalam olahraga merupakan usaha yang dilakukan melalui pembinaan diusia dini baik dari kemampuan teknik taktik dan strategi serta melalui pendekatan ilmiah. Mendapatkan prestasi yang setinggi-tingginya diperlukan yang namanya usaha dan kerja keras yang latihannya sudah terencana dan terukur yang sesuai dengan cabang olahraga yang didalami.

Sepakbola merupakan olahraga dalam bentuk permainan yang sudah dikenal diseluruh dunia dan lingkungan sekitar kita, karena setiap lapisan masyarakat sudah mengenal dan dapat memainkan olahraga ini. Karena sepakbola adalah suatu cabang olahraga yang sederhana dan menyenangkan untuk dimainkan yang semuanya melibatkan pergerakan-pergerakan tubuh menjadi sehat yang di dalamnya terdapat aktivitas seperti gerakan lari, melompat, melempar dan menendang bola. Teknik dasar bermain sepakbola terdiri dari: teknik menendang, teknik menahan bola, teknik menggiring bola, teknik gerak tipu, teknik menyundul bola, teknik merebut bola, dan teknik lemparan ke dalam yang baik dan benar.

Menguasai teknik juga belum cukup tanpa ditunjang dengan kondisi fisik pemain tersebut, misalnya kekuatan, kelentukan, kecepatan, dan kelincahan. Contohnya dalam mengoper bola jarak jauh (long passing) di butuhkan kekuatan dan kecepatan kaki serta daya ledak (power) saat kaki mengenai bola yang akan di tendang. Hal tersebut harus dimiliki seorang pesepakbola agar dapat melakukan menendang bola dan bola yang di tendang hasilnya jauh dan terarah.

Salah satu faktor kondisi fisik yang mempengaruhi kualitas tendangan adalah power otot tungkai. Power otot tungkai sangat menentukan kemampuan seorang pemain untuk melakukan tendangan dalam bermain sepakbola, karena power merupakan gabungan dari kekuatan dan kecepatan. Jika seorang pemain sepakbola mempunyai teknik menendang dan power otot tungkai yang baik maka tendangannya akan baik juga. Bentuk latihan menendang dengan menggunakan bending dan latihan menendang dengan menggunakan karet adalah metode latihan untuk meningkatkan daya ledak otot tungkai.

Daya ledak (power) otot tungkai sangat dibutuhkan pada waktu melakukan tendangan jauh sehingga tendangan akan lebih kuat, dengan demikian dapat dikatakan bahwa metode latihan menendang dengan bending dan menendang dengan karet dapat diberikan untuk meningkatkan power otot tungkai sehingga kemampuan tendangan long passing atlet sepakbola Klumpang Putra dapat dilakukan dengan baik.

Berdasarkan hasil pengamatan yang dilakukan peneliti bahwa pada saat games di lapangan sering terjadi kesalahan-kesalahan pada saat melakukan passing, terutama passing jarak jauh. Kemudian hasil diskusi yang dilakukan peneliti dengan pelatih bahwa pemain Sekolah Sepakbola Klumpang Putra usia 13-14 Tahun masih memiliki kekurangan dalam melakukan tendangan jarak jauh (long passing). Oleh karena itu, perlu diterapkan metode latihan yang tepat untuk meningkatkan otot power. Latihaan di SSB Klumpang Putra lebih difokuskan pada bermain dan latihan teknik, latihan yang mengarah ke latihan fisik khususnya untuk meningkatkan power otot tungkai masih kurang diperhatikan. Berdasarkan hasil observasi tersebut, maka dugaan sementara peneliti bahwa pemain 
Sekolah Sepakbola Klumpang Putra memiliki kekurangan pada power otot tungkai sehingga kemampuan dalam menendang jarak jauh kurang baik.

Untuk memperkuat dugaan tersebut, maka peneliti melakukan tes pendahuluan berupa tes standing broad jump dan tes long passing untuk memperoleh gambaran sejauh mana kemampuan power otot tungkai dan tendangan long passing yang dimiliki pemain Sekolah Sepakbola Klumpang Putra. Hasil dari test standing broad jump pemain sepakbola SSB Klumpang Putra Usia 13-14 Tahun yaitu: 1 orang dengan kategori lemah dan 19 orang dengan kategori sangat lemah, sehingga perlu diberikan latihan yang dapat meningkatkan power otot tungkai sehingga meningkatkan hasil long passing dapat menjadi lebih baik pula. Banyak bentuk latihan yang dapat digunakan untuk meningkatkan power otot tungkai seperti plyometrics dan latihan beban. Bompa (1994:158) mengemukakan bahwa "latihan plyometrics dapat meningkatkan power otot tungkai". Hal senada juga dikemukakan oleh A Chu (2000:81) bahwa "plyometrics merupakan latihan khusus yang melatih otototot untuk menghasilkan kekuatan maksimum dengan lebih cepat". Dari beberapa bentuk latihan beban yang ada, dalam penelitian ini peneliti memilih bentuk latihan yang mirip dengan gerakan menendang bola ke depan, bentuk latihannya adalah menendang dengan menggunakan bending dan menendang dengan menggunakan karet.

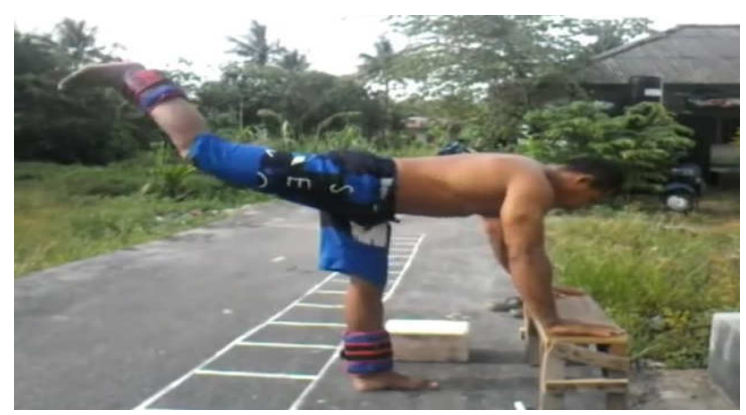

Gambar 1. Latihan Bending (Sumber: https://youtu.be/DAdLYLxCaJA)

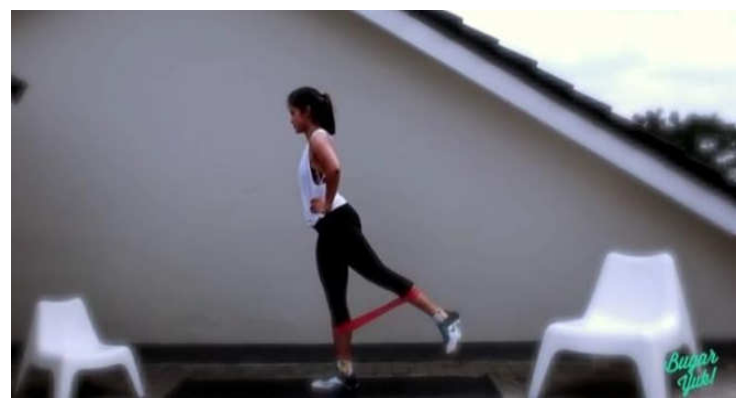

Gambar 2. Latihan Karet (Sumber: https//youtu.be/bXdmjzwJ6yE)

Latihan beban ini pada prinsipnya mengembangkan kemampuan power otot tungkai yang bertujuan untuk dapat melakukan tendangan jarak jauh dalam permainan sepakbola. Dari uraian diatas maka peneliti tertarik untuk melakukan penelitian tentang perbedaan pengaruh latihan menendang menggunakan bending dan latihan menendang menggunakan karet terhadap power otot tungkai dan hasil long passing sepakbola pada usia 13-14 tahun Sekolah Sepakbola Klumpang Putra.

Sepakbola adalah permainan yang dilakukan menggunakan kaki dengan bola sebagai media. Tujuan utamanya adalah mencetak gol atau skor sebanyak-banyaknya dan harus sesuai dengan peraturan yang telah ditentukan. Sepakbola adalah sebuah permainan yang sederhana dan rahasia. 
Permainan sepakbola yang baik adalah melakukan hal-hal sederhana dengan sebaik-baiknya, Batty (2011:4). Bentuk latihan menendang dengan menggunakan bending dan latihan menendang dengan menggunakan karet adalah metode latihan untuk meningkatkan daya ledak otot tungkai. Daya ledak (power) otot tungkai sangat dibutuhkan pada waktu melakukan tendangan jauh sehingga tendangan akan lebih kuat, dengan demikian dapat dikatakan bahwa metode latihan menendang dengan bending dan menendang dengan karet dapat diberikan untuk meningkatkan power otot tungkai sehingga kemampuan tendangan long passing atlet sepakbola Klumpang Putra dapat dilakukan dengan baik.

\section{METODE}

Penelitian ini dilaksanakan di lapangan klub Sekolah sepakbola (SSB) Klumpang Putra, Sunggal Deli Serdang. Waktu penelitian berlangsung pada bulan September sampai November tahun 2019 dengan frekuensi latihan 3 kali seminggu. Metode latihan yang digunakan adalah metode eksperimen, latihan menendang menggunakan bending dan latihan menendang menggunakan karet sebagai variabel bebas dan peningkatan power otot tungkai dan hasil long passing sebagai variabel terikat. Sebelum sampel melakukan latihan terlebih dahulu dilakukan pre-test (tes awal) untuk mengetahui power otot tungkai dan hasil long passing atlet. Setelah mengetahui kemampuan power otot tungkai dan hasil long passing, kemudian atlet di matching dan diberi perlakuan Menendang menggunakan bending dan Menendang menggunakan karet sesuai hasil dari matching. Kemudian setelah diberikan latihan selama 18 kali pertemuan dilakukan post-test (tes akhir).

Data yang diperoleh dari hasil pre-test adalah data mentah yang selanjutnya diolah dengan menggunakan prosedur statistik untuk membuktikan apakah hipotesis yang diujikan dalam penelitian ini dapat diterima atau ditolak. Data yang telah terkumpul dari pre-test dan post-test dianalisis dengan menggunakan statistik uji-t, uji normalitas dan uji homogenitas yang diuji dengan bantuan program SPSS. Pertama dilakukan tes awal sebanyak 20 orang siswa Sekolah Sepakbola Klumpang Putra Usia 13-14 Tahun. Setelah sampel diperoleh dari populasi yang diambil dengan teknik purposive sample, maka selanjutnya diadakan tes awal untuk mengetahui kemampuan awal sampel terhadap power otot tungkai dan long passing.

Setelah data tes awal didapat, maka sampel dibagi menjadi dua kelompok dengan teknik matching pairing sesuai dengan urutan hasil tes power otot tungkai yang dilakukan tiga kali kesempatan dan hasil yang diambil adalah hasil terbaik. Tiap kelompok terdiri dari 10 orang, setelah itu baru diberi perlakuan latihan menendang dengan bending satu kelompok sesuai dengan program latihan. Satu kelompok lagi diberi perlakuan latihan menendang dengan karet. Kemudian setelah latihan 6 minggu berjalan dalam 18 kali frekuensi latihan 3 kali seminggu maka pada minggu ke 6 juga dilakukan tes akhir (post-test) untuk mengetahui kemampuan power otot tungkai dan long passing. Setelah dapat pre-test dan post-test maka selanjutnya dilakukan perhitungan melalui rumus statistik untuk membuktikan hipotesis yang dilakukan benar atau tidak.

\section{HASIL DAN PEMBAHASAN}

Hasil tes dan pengukuran yang dilakukan dilapangan selama penelitian merupakan temuan peneliti yang dilakukan selama 18 pertemuan. Penelitian dilakukan untuk mengungkapkan kebenaran hipotesis, hasil tes dan pengukuran yang telah diolah melalui rumus statistik. Berhasil tidaknya long passing bergantung pada kemampuan teknis penendang. Pada pelaksanaan long passing ada beberapa hal yang harus diperhatikan, antara lain kaki tumpuan harus berada tepat di sisi bola, posisi kaki ayun, perkenaan bola yang ditendang, sikap badan dari awal menendang, hingga sikap membuang badan setelah menendang, hingga pandangan mata yang harus memperhatikan bola dan kawan sekaligus. 
Tabel 1. Pre-Test dan Post-Test Latihan Menendang Menggunakan Bending dan Latihan Menendang Menggunakan Karet Terhadap Peningkatan Power Otot Tungkai

\begin{tabular}{lcccc}
\hline & \multicolumn{3}{c}{ Peningkatan Power Otot Tungkai } \\
\cline { 2 - 5 } Deskripsi Data & \multicolumn{2}{c}{ Menggunakan Bending } & \multicolumn{2}{c}{ Menggunakan Karet } \\
\cline { 2 - 5 } Pre-Test & Post-Test & Pre-Test & Post-Test \\
\hline Rentang & $180-$ & $186-220$ & $187-$ & $190-220$ \\
& 220 & & 220 & \\
\hline Nilai Rata-Rata & 204.6 & 203.1 & 202.5 & 202.7 \\
\hline Simpangan Baku & 12.57 & 12.99 & 10.51 & 9.86 \\
\hline
\end{tabular}

(Sumber: Data Penelitian, 2019)

Dari hasil pre-test pada latihan menggunakan bending terhadap hasil peningkatan power otot tungkai diperoleh rentang antara 180-220 dengan nilai rata-rata 204.6 dan simpangan baku12.57. Dari hasil post-test diperoleh rentang 186-220 dengan nilai rata-rata 203.1 dan simpangan baku 12.99. Dari hasil pre-test pada latihan menggunakan karet terhadap hasil peningkatan power otot tungkai diperoleh rentang antara 187-220 dengan nilai rata-rata 202.5 dan simpangan baku10.51. Dari hasil post-test diperoleh rentang 190-220 dengan nilai rata-rata 202.7 dan simpangan baku 9.86.

Tabel 2. Pre-Test dan Post-Test Latihan Menendang Menggunakan Bending dan Latihan Menendang Menggunakan Karet Terhadap Hasil Peningkatan Long Passing

\begin{tabular}{|c|c|c|c|c|}
\hline \multirow{3}{*}{ Deskripsi Data } & \multicolumn{4}{|c|}{ Hasil Long passing } \\
\hline & \multicolumn{2}{|c|}{$\begin{array}{c}\text { Menendang } \\
\text { Menggunakan Bending }\end{array}$} & \multicolumn{2}{|c|}{$\begin{array}{c}\text { Menendang } \\
\text { Menggunakan Karet }\end{array}$} \\
\hline & Pre-Test & Post-Test & Pre-Test & Post-Test \\
\hline Rentang & $17.1-28.16$ & $20.38-30.1$ & $18.86-27.8$ & $20.68-28.48$ \\
\hline Nilai Rata-Rata & 23.30 & 25.17 & 23.49 & 25.05 \\
\hline Simpangan Baku & 3.35 & 2.97 & 2.94 & 2.84 \\
\hline
\end{tabular}

(Sumber: Data Penelitian, 2019)

Dari hasil pre-test pada latihan menendang menggunakan bending terhadap hasil long passing diperoleh rentang antara 17.1- 28.16 dengan nilai rata-rata 23.30 dan impangan baku 3.35. Dari hasil post-test diperoleh rentang 20.38-30.1 dengan nilai rata-rata 25.17 dan simpangan baku 2.97. Dari hasil pre-test pada latihan menendang menggunakan karet terhadap hasil long passing diperoleh rentang antara 18.86 - 27.8 dengan nilai rata-rata 23.49 dan simpangan baku 2.94. Dari hasil post- test diperoleh rentang 20.68-28.48 dengan nilai rata-rata 25.05 dan simpangan baku 2.84. Dari hasil pretest pada latihan menggunakan bending terhadap hasil peningkatan power otot tungkai diperoleh rentang antara 180-220 dengan nilai rata-rata 204.6 dan simpangan baku 12.57. Dari hasil post-test diperoleh rentang 186-220 dengan nilai rata-rata 203.1 dan simpangan baku 12.99.

Dari hasil pre-test pada latihan menggunakan karet terhadap hasil peningkatan power otot tungkai diperoleh rentang antara 187-220 dengan nilai rata-rata 202.5 dan simpangan baku10.51. Dari hasil post-test diperoleh rentang 190-220 dengan nilai rata-rata 202.7 dan simpangan baku 9.86. Dari hasil pre-test pada latihan menendang menggunakan bending terhadap hasil long passing diperoleh rentang antara 17.1-28.16 dengan nilai rata-rata 23.30 dan simpangan baku 3.35. Dari hasil post-test diperoleh rentang 20.38-30.1 dengan nilai rata-rata 25.17 dan simpangan baku 2.97.

Dari hasil pre-test pada latihan menendang menggunakan karet terhadap hasil long passing diperoleh rentang antara $18.86-27.8$ dengan nilai rata-rata 23.49 dan simpangan baku 2.94. Dari hasil post-test diperoleh rentang 20.68-28.48 dengan nilai rata-rata 25.05 dan simpangan baku 2.84 . Uji normalitas adalah sebuah uji yang dilakukan dengan tujuan untuk menilai sebaran data pada sebuah 
kelompok data atau variabeL. Uji normalitas berguna untuk menentukan data yang telah dikumpulkan berdristibusi normal atau diambil dari populasi normal.

Berdasarkan hasil uji normalitas yang telah dilakukan dapat diketahui bahwa seluruh data dalam penelitian ini berdistribusi normal dapat dilihat dari semua nilai sig $>0.05$ Uji homogenitas adalah pengujian mengenai sama tidaknya varians dua buah distribusi atau lebih. Uji homogenitas dilakukan untuk mengetahui apakah data variable dalam penelitian bersifat homogen atau tidak.Dari hasil pengujian dapat diketahui bahwa semua data penelitian bersifat homogen dilihat dari semua nilai signifikan $>0.05$.

Sepakbola merupakan olahraga yang tidak asing lagi di Indonesian begitupun di dunia. Setiap orang baik laki-laki maupun perempuan, tua maupun muda, mengetahui sepakbola walaupun dari sebagian dari mereka hanya sekedar mengetahui saja dan tidak bias untuk memainkannya, tapi hal tersebut sudah cukup untuk membuktikan bahwa sepakbola merupakan olahraga yang paling popular di dunia. Power merupakan suatu unsur diantara unsur-unsur komponen kondisi fisik yaitu kemampuan biomotorik manusia, yang dapat ditingkatkan sampai batas-batas tertentu dengan melakukan latihan-latihan tertentu yang sesuai.

Power atau daya ledak menyangkut kekuatan dan kecepatan kontraksi otot yang dinamis dan explosive serta melibatkan pengeluaran kekuatan otot yang maksimal dalam waktu yang secepatcepatnya. Bending adalah merupakan salah satu alat atau beban yang sering dipergunakan atlet untuk melatih otot-otot sesuai dengan cabang olahraga yang ditekuni. Selain melatih kekuatan otot, bending juga dapat digunakan untuk melatih kecepatan dan kekuatan power otot tungkai. Latihan-latihan menggunakan bending ini juga menawarkan gerakan pasif dan stres yang rendah pada tubuh karena tidak menggunakan gerak sebagai bagian dari latihan. Seperti bentuk-bentuk lain dari latihan ketahanan, memakai beban pergelangan kaki dapat membantu membangun otot dan kekuatan dengan meningkatkan kesulitan dan intensitas berbagai latihan. Karena beban pergelangan kaki kencangkan langsung ke kaki umumnya nyaman dan dapat diintegrasikan ke dalam berbagai kegiatan. Untuk pemain sepakbola, kemampuan beban pergelangan kaki untuk meningkatkan kekuatan kaki dapat menawarkan keuntungan untuk melakukan long passing.

Bentuk latihan dengan menggunakan beban karet secara fundamental mengadopsi dari latihan tahanan yaitu menarik beban karet sebagai bahan yang diikatkan pada bagian tungkai bawah, hal ini dapat menunjukkan suatu pengembangan yang di tujukan ke salah satu bagian tubuh tertentu, terutama pada bagian tungkai. Bahwa kondisi fisik yang di kehendaki dapat di kembangkan melalui latihan beban karet ini. Latihan berbeban karet pada tungkai adalah suatu bentuk latihan yang memanfaatkan beban luar berupa karet yang di ikatkan pada pergelangan kaki. Latihan beban karet akan melatih kontraksi otot, selama latihan beban karet kontraksi otot yang terjadi yaitu kontraksi otot secara isokenetik. Kontraksi otot isokenetik adalah kontraksi otot secara maksimal dengan kecepatan kontraksi konstan. Kontraksi semacam ini adalah kontraksi otot selama kegiatan olahraga berlangsung.

Berdasarkan uji hipotesis latihan menendang menggunakan karet terhadap peningkatan power otot tungkai menunjukkan pengaruh yang signifikan. Hasil penelitian tersebut membuktikan prinsip olahraga yakni jika latihan dilakukan dengan benar dan dengan porsi yang benar akan dapat meningkatkan kemampuan seseorang. Melalui latihan beban secara teratur serta beban latihannya ditambah sedikit demi sedikit secara progresif akan merangsang otot tungkai berkontraksi secara cepat, sehingga menimbulkan kekuatan dan kecepatan yang besar disertai daya ledak.

Pengujian hipotesis pertama menunjukkan bahwa Terdapat pengaruh yang signifikan dari latihan menendang menggunakan bending terhadap peningkatan power otot tungkai pada atlet sekolah sepakbola Klumpang Putra usia 13-14 tahun. Berdasarkan hasil perhitungan yang dilakukan, maka diperoleh pengujian hipotesis $\left(t_{\text {hitung }}\right)$ sebesar 10.046. Selanjutnya dibandingkan dengan nilai $t_{\text {tabel }}$ dengan $\mathrm{dk} n-\mathrm{k}(10-1=9)$ pada taraf signifikan $\alpha 0,05$ adalah 1.833 dengan demikian $\mathrm{t}_{\text {hitung }}>\mathrm{t}_{\text {tabel }}$ $(10.046>1.833)$.

Pengujian hipotesis kedua menunjukkan bahwa terdapat pengaruh yang signifikan dari latihan menendang menggunakan karet terhadap peningkatan power otot tungkai pada atlet sekolah sepakbola Klumpang Putra usia 13-14 tahun. Berdasarkan hasil perhitungan yang dilakukan, maka diperoleh 
pengujian hipotesis ( $\mathrm{t}_{\text {hitung }}$ ) sebesar 5.377. Selanjutnya dibandingkan dengan nilai $\mathrm{t}_{\text {tabel }}$ dengan $\mathrm{dk} \mathrm{n}-\mathrm{k}$ $(10-1=9)$ pada taraf signifikan $\alpha 0,05$ adalah 1.833 dengan demikian $t_{\text {hitung }}>t_{\text {tabel }}(5.377>1.833)$.

Pengujian hipotesis ketiga menunjukkan bahwa Latihan menendang menggunakan bending secara signifikan lebih baikdari pada latihan menggunakan karet terhadap peningkatan power otot tungkai pada atlet sekolah sepakbola Klumpang Putra usia 13-14 tahun. Berdasarkan hasil perhitungan yang dilakukan, maka diperoleh pengujian hipotesis $\left(\mathrm{t}_{\text {hitung }}\right)$ sebesar $-1,168$. Selanjutnya dibandingkan dengan nilai tabel dengan $\mathrm{dk}_{1}+\mathrm{n}_{2}-2(20-2=18)$ pada taraf signifikan $\alpha 0,05$ adalah 1.734 dengan demikian $\mathrm{t}_{\text {hitung }}<\mathrm{t}_{\text {tabel }}(4.744>1.734)$.

Pengujian hipotesis keempat menunjukkan bahwa terdapat pengaruh yang signifikan dari latihan menendang menggunakan bending terhadap hasil long passing pada atlet sekolah sepakbola Klumpang Putra usia 13-14 tahun. Berdasarkan hasil perhitungan yang dilakukan, maka diperoleh pengujian hipotesis ( $\mathrm{t}_{\text {hitung }}$ ) sebesar 6.022. Selanjutnya dibandingkan dengan nilai $\mathrm{t}_{\text {tabel }}$ dengan $\mathrm{dk} \mathrm{n}-\mathrm{k}$ $(10-1=9)$ pada taraf signifikan $\alpha 0,05$ adalah 1.833 dengan demikian $t_{\text {hitung }}>t_{\text {tabel }}(6.022>1.833)$.

Pengujian hipotesis kelima menunjukkan bahwa ada terdapat pengaruh yang signifikan dari latihan menendang menggunakan karet terhadap hasil long passing pada atlet sekolah sepakbola Klumpang Putra usia 13-14 tahun. Berdasarkan hasil perhitungan yang dilakukan, maka diperoleh pengujian hipotesis ( $\mathrm{t}_{\text {hitung }}$ ) sebesar 7.508. Selanjutnya dibandingkan dengan nilai $\mathrm{t}_{\text {tabel }}$ dengan $\mathrm{n}-\mathrm{k}$ $(10-1=9)$ pada taraf signifikan $\alpha 0,05$ adalah 1.833 dengan demikian $t_{\text {hitung }}>t_{\text {tabel }}(7.508>1.833)$.

Pengujian hipotesis keenam menunjukkan bahwa latihan menendang menggunakan bending tidaklebih besar pengaruhnya dari pada latihan menggunakan karet terhadap peningkatan hasil long passing pada atlet sekolah sepakbola Klumpang Putra usia 13-14 tahun.Berdasarkan hasil perhitungan yang dilakukan, maka diperoleh pengujian hipotesis ( $\mathrm{t}_{\text {hitung }}$ ) sebesar 0,944 . Selanjutnya dibandingkan dengan nilai tabel dengan $\mathrm{dk}_{1}+\mathrm{n}_{2}-2(20-2=18)$ pada taraf signifikan $\alpha 0,05$ adalah 1.734 dengan demikian $\mathrm{t}_{\text {hitung }}<\mathrm{t}_{\text {tabel }}(0,252<1.734)$.

\section{SIMPULAN}

Berdasarkan hasil tes yang telah dilakukan, maka penelitian dapat disimpulkan sebagai berikut: 1) Terdapat pengaruh yang signifikan dari latihan menendang menggunakan bending terhadap peningkatan power otot tungkai pada atlet sekolah sepakbola Klumpang Putra usia 13-14 tahun, 2). Terdapat pengaruh yang signifikan dari latihan menendang menggunakan karet terhadap peningkatan power otot tungkai pada atlet sekolah sepakbola Klumpang Putra usia 13-14 tahun, 3) Latihan menendang menggunakan bending secara signifikan lebih baik dari pada latihan menggunakan karet terhadap peningkatan power otot tungkai pada atlet sekolah sepakbola Klumpang Putra usia 13-14 tahun, 4) Terdapat pengaruh yang signifikan dari latihan menendang menggunakan bending terhadap hasil long passing pada atlet sekolah sepakbola Klumpang Putra usia 13-14 tahun. 5) Terdapat pengaruh yang signifikan dari latihan menendang menggunakan karet terhadap hasil long passing pada atlet sekolah sepakbola Klumpang Putra usia 13-14 tahun, 6) Latihan menendang menggunakan bending tidak lebih baik dari pada latihan menggunakan karet terhadap peningkatan hasil long passing pada atlet sekolah sepakbola Klumpang Putra usia 13-14 tahun.

Berdasarkan kesimpulan yang diperoleh dari penelitian untuk melihat perbedaan pengaruh dari dua metode latihan yang bertujuan untuk peningkatan power otot tungkai dan hasil long passing dalam permainan sepakbola. Berikut dikemukakan beberapa hal yang dapat menjadi pertimbangan, yaitu kepada pelatih agar dapat menggunakan latihan menggunakan bendingdengan latihan menggunakan karet dan latihan lain yang kemungkinan dapat berpengaruh terhadap power otot tungkai dan hasil long passing pada permainan sepakbola, kemudian kepada peneliti selanjutnya yang hendak melakukan penelitian sejenis agar dapat meneliti faktor lain yang mungkin dapat berpengaruh terhadap power otot tungkai dan hasil long passing pada permainan sepakbola. 


\section{DAFTAR PUSTAKA}

Baechle, Thomas R \& Roger W Earle. (2002). Bugar Dengan Latihan Beban. Jakarta: Raja Grafindo Persada.

Batty, Eric C. (2011). Latihan Metode Baru Sepak Bola Serangan. Bandung: Pionir Jaya.

Bompa Tudor'O. (1994). Theory And Methodology Of Training. Dubuque, lowa: Kendal/Hunt Publishing Company.

Donal, A Chu. (1985). Jumping In To Plyometrics. Champaign, Illionis: Leisure Press.

Gilang, Angga. (2007). Pendidikan Jasmani Olahraga Kesehatan. Jakarta: Grandfindo Media Pratama.

Harsono. (1988). Coaching Dan Aspek-aspek Psikologis Dalam Coaching. Jakarta: Departemen Pendidikan dan Kebudayaan, Proyek Pengembangan Lembaga Pendidikan, Tenaga Kependidikan.

Imran Akhmad. (2013). Dasar-Dasar Melatih Fisik Olahragawan. Medan: Unimed Press.

Ismaryati. (2008). Tes dan Pengukuran Olahraga. Surakarta: LPP dan Press UNS.

Iqbal Ikhlas. (2016). Pengaruh Modifikasi Latihan Beban Terhadap Kemampuan Tendangan Long Passing Dalam Permainan Sepak Bola Pada Kegiatan Ekstra Kurikuler Sepak Bola SMA N 1 Palembang. Palembang: UNSRI.

Luxbacher Jhosep A. (2011). Sepak Bola. Jakarta: PT Grandfindo Media Prasada.

Mukholid. (2004). Pendidikan Jasmani dan Olahraga Kesehatan. Jakarta: Grandfindo Media Pratama.

Putra, Kharisma. (2012). Peningkatan Hasil Belajar Teknik Dasar Tendangan Jarak Jauh dalam Sepak Bola Melalui Penerapan Model Belajar Team Games Tournamen pada Siswa Kelas VII SMP Veteran I Manyaran Kabupaten Wonogiri Tahun Pelajaran 2012/2013. Surakarta: Universitas Sebelas Maret.

Soekatamsi. (2002). Permainan Bola Besar I. Jakarta: Depdikbud.

Sucipto, dkk. (2006). Teknik Dasar Sepak Bola. Jakarta: Rineka Cipta.

Sudjana. (1992). Metode Statistik. Bandung: Tarsito.

Yudik \& Ahmad. (2014). Latihan Beban.Com. 